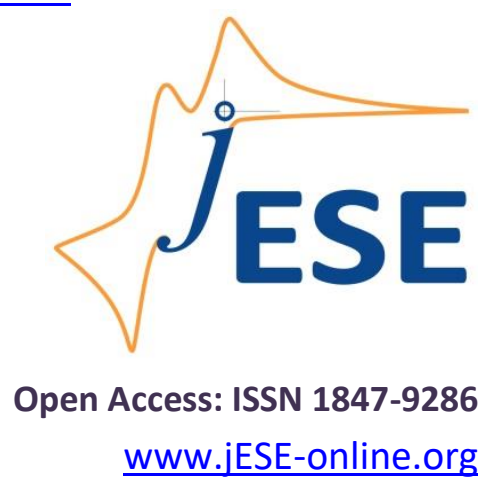

Review

\title{
Gas sensing technologies in combustion: A comprehensive review
}

\author{
Ulrich Guth ${ }^{1, \bigotimes}$, Pavel Shuk ${ }^{2}$, Chad McGuire ${ }^{2}$ \\ ${ }^{1}$ Technische Universität Dresden, D-01062 Dresden, Germany \\ ${ }^{2}$ Rosemount Measurement and Analytical, Emerson Electric Corp, Shakopee, MN 55379, USA \\ Corresponding author: ${ }^{凶}$ ulrich.guth@chemie.tu-dresden.de; Tel.: +49 351 46337597; \\ Fax: +4935146337164
}

Received: October 31, 2020; Revised January 9, 2020; Accepted: January 20, 2020

\begin{abstract}
Irrespective of the change in kind of energy to renewables there are many processes in which combustion of conventional fuels and biofuel are necessary. For cement and glass production, paper fabrication and air traffic it is absolutely essential to control the combustion processes by intelligent sensors in order to maximize the efficiency and to minimize the emission of harmful substances such as $\mathrm{NO}_{x}$ and $\mathrm{CO}$. Mainly oxygen sensors based on solid electrolytes and calorimetric sensors using the heat formation by catalytic combustion of $\mathrm{CO}$ and hydrocarbons with two resistance temperature detectors (RTD) are utilized. Recently, tunable diode laser spectroscopy (TDLS) became attractive in chemical plants. Several analytical companies are offering in-situ or extractive laser analyzers for combustion gases.
\end{abstract}

\section{Keywords}

Combustion control; in situ sensors for oxygen and hydrocarbons; solid electrolyte sensors; calorimetric sensors; tunable diode laser spectroscopy.

\section{Combustion process}

The combustion of fuel is a complex process which has to be carried out in a small operation window concerning the air/fuel ratio. By reasons of economy as well as restriction of law the main components as oxygen and unburnt species ( $\mathrm{CO}$ and hydrocarbons) have to be measured in situ to gain real-time information. $\mathrm{NO}_{\mathrm{x}}$ as the main pollutant must be measured at the end of exhaust to ensure the regulations by law. An overview on the concentrations of combustion flue gases and the small operation window is given in Figures 1 and 2.

Due to the high viscosity of flue gases the concentration of oxygen and $\mathrm{CO}$ is local-dependent (stratification) so that several sensors have to be installed to obtain an average value of oxygen and combustibles (Figure 3). 


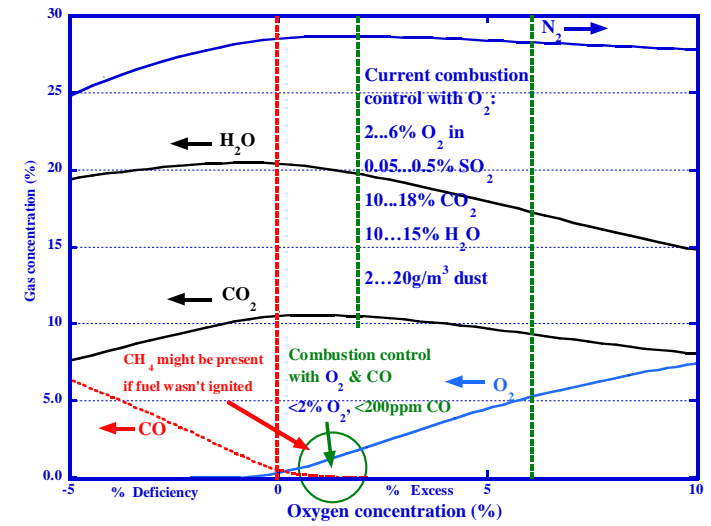

Figure 1. Combustion flue gas diagram and a need to measure $\mathrm{O}_{2}, \mathrm{CO}, \mathrm{CH}_{4}[1]$

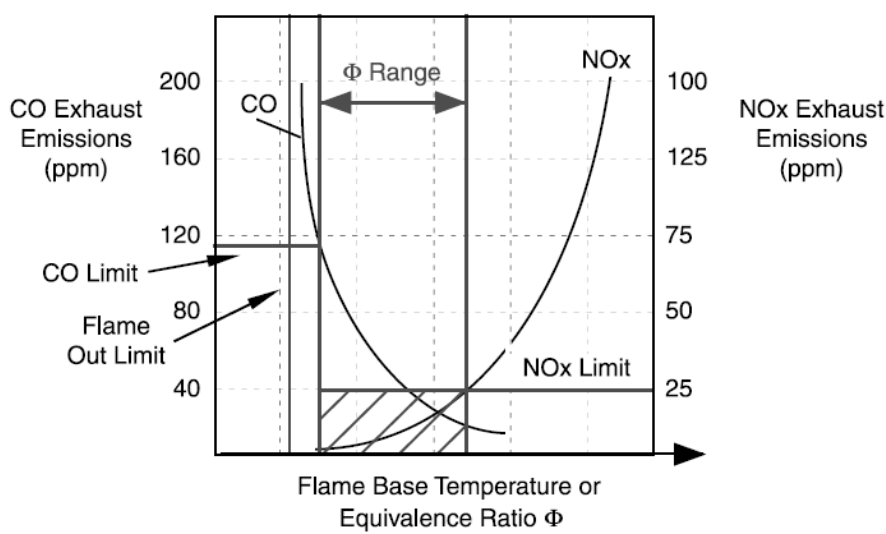

Figure 2. Active combustion control (after [2])

There are several technologies for combustion process gases monitoring (Figure 4). Only few of them, such as electrochemical high temperature sensors, calorimetric sensors and laser techniques, are suitable to measure in situ across stack application. The last one is expensive as compared with solid electrolyte sensors and it needs some effort for maintenance.

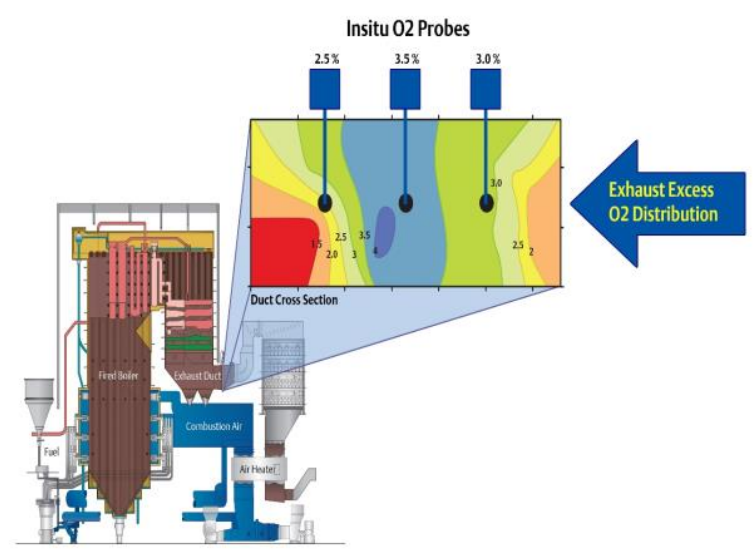

Figure 3. Combustion process regulation: Flue gas stratification ( $\mathrm{O}_{2}$ content, \%) [3]

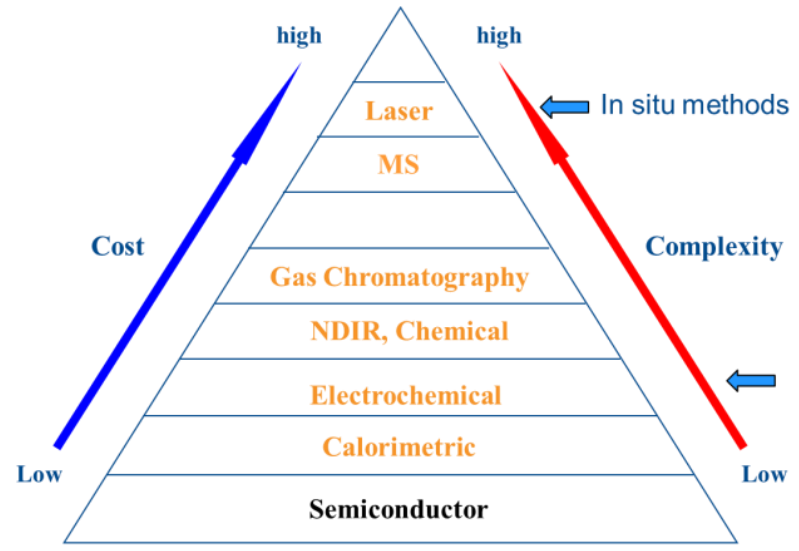

Figure 4. Sensor principles for combustion control

\section{Solid electrolyte sensors}

Electrochemical oxygen sensors based on zirconia solid electrolytes, which are widely used today in different industrial applications and for controlling fuel/air ratio in internal combustion engines (lambda sensor), were first introduced $\sim 60$ years ago by Peters and Möbius (Germany) [4] and Weissbart and Ruka (Westinghouse, USA) [5]. An overview on the basic principles of solid electrolyte sensors is given in Figure 5 [6]. Common to all these sensors is the high operation temperature which is necessary to ensure high electrochemical kinetics for the oxygen exchange within the electrodes and sufficient conductivity of the solid electrolyte. On the other hand, it allows a high operation temperature to be measured in hot gases such as in or near the combustion chamber. Most industrial zirconia oxygen sensors are based on electrochemical cells with stabilized zirconia solid electrolytes operating in potentiometric mode [7-12]. This electrochemical cell is made of zirconia solid electrolyte (mostly yttrium stabilized zirconia, YSZ) and two platinum electrodes printed and sintered on the opposite sides of a dense zirconia ceramics and exposed to the process and reference gases, respectively. Gas-tight sintered ceramics is formed as tubes, discs, planar substrates or thick films. Zirconia sensors are supplied as steel or ceramic probes up to $4 \mathrm{~m}$ in length. 
The service life depends on application temperature and loads of pollutants and can be up to 510 years. Several producers from US (Emerson, Ametec), Japan (Yokogawa) and Germany (ENOTEC, Zirox, STG) are on the market. YSZ based oxygen sensors can be applied not only for optimization of combustion, but also to measure in processes in which reducing or oxidizing gases are necessary in order to ensure a certain oxidation state. That is important for the production of ceramics, porcelain, bricks.

\begin{tabular}{|c|c|c|c|}
\hline potentiometric & mixed potential & amperometric & coulometric \\
\hline meas- & $\begin{array}{c}\text { meas- } \\
\text { uring } \\
\text { gas } \\
\mathrm{HC} \\
\mathrm{NO}_{\mathrm{X}} \\
\mathrm{O}_{2}\end{array}$ & diffusion barrier & $\begin{array}{cc} \\
\text { meas- } \\
\text { uring } \\
\text { gas } \\
\text { r( }\left(\mathrm{O}_{2}\right) \\
800^{\circ} \mathrm{C}\end{array}$ \\
\hline \multicolumn{4}{|l|}{ sensor function } \\
\hline$U_{c}=\frac{R T}{z F} \ln \frac{p_{\mathrm{O}_{2}}^{\prime}}{p_{\mathrm{O}_{2}}^{\prime \prime}}$ & $U_{m}=U_{0}-A \ln p_{H C}$ & $I_{d} \cong p\left(O_{2}\right)$ & $I_{F}=\dot{n}\left(O_{2}\right) z F$ \\
\hline \multicolumn{4}{|l|}{ measuring range } \\
\hline $10^{-30} \ldots 10 \mathrm{bar}$ & $1 \ldots 20000$ vol.-ppm & $10^{-4} \ldots 1 \mathrm{bar}$ & $10^{-5} \ldots 1 \mathrm{bar}$ \\
\hline
\end{tabular}

Figure 5. Basic working principles of solid electrolyte sensors for oxygen containing gases. The equations refer to the measured signals [6]

Oxidizing and reducing states differ in Nernst's Voltage (Figure 6). At the lambda-leap $(\lambda=1)$ the equilibrium potential changes abruptly. In the 1960 s and 1970 s the limits of measurement in terms of temperature and oxygen partial pressure have been determined [7]. Sometimes the load of the flue gas with sulfur cause problems regarding the poisoning of electrode material [13]. Hence, nowadays there are only few research activities in this field [14].

For automotive applications, lambda probes (oxygen sensors) are based on the potentiometric or combined potentiometric and amperometric dual sensing technologies $[8,9]$. Such sensors are produced in millions of pieces by thick film techniques in a co-firing process. Recently, mixed potential sensors for $\mathrm{CO}$ and hydrocarbons were developed $[15,16]$ and are commercially available in Germany by Lamtec and Enotec. The components in flue gas like $\mathrm{CO}$, hydrocarbons $\left(\mathrm{H}_{\mathrm{x}} \mathrm{C}_{\mathrm{y}}\right)$, nitric oxides $\left(\mathrm{NO}_{\mathrm{x}}\right)$ and residual oxygen $\left(\mathrm{O}_{2}\right)$ to be measured do not equilibrate at temperatures $<700{ }^{\circ} \mathrm{C}$ in the vicinity of the hot electrode. Thus, gas components which are not thermodynamically stable are electrochemically active. In hydrocarbons and oxygen containing atmosphere at least two electrode reactions can take place: oxygen electrochemical reduction and electrochemical oxidation of hydrogen or other combustibles (Figure 7). The measured open circuit voltage, also called mixed potential, does not obey the Nernst equation but depends logarithmically on the concentration of $\mathrm{CO}$, methane or hydrocarbons. Low catalytic activity materials such as gold or gold platinum alloys are usually employed for these sensors combined with catalytically active Pt-electrode.

In many cases composite materials consisting of gold and oxides show a high sensitivity to $\mathrm{CO}$ as can be seen in Figure 8. Furthermore, complex perovskite-type oxides are very promising sensitive materials (Figure 9). 


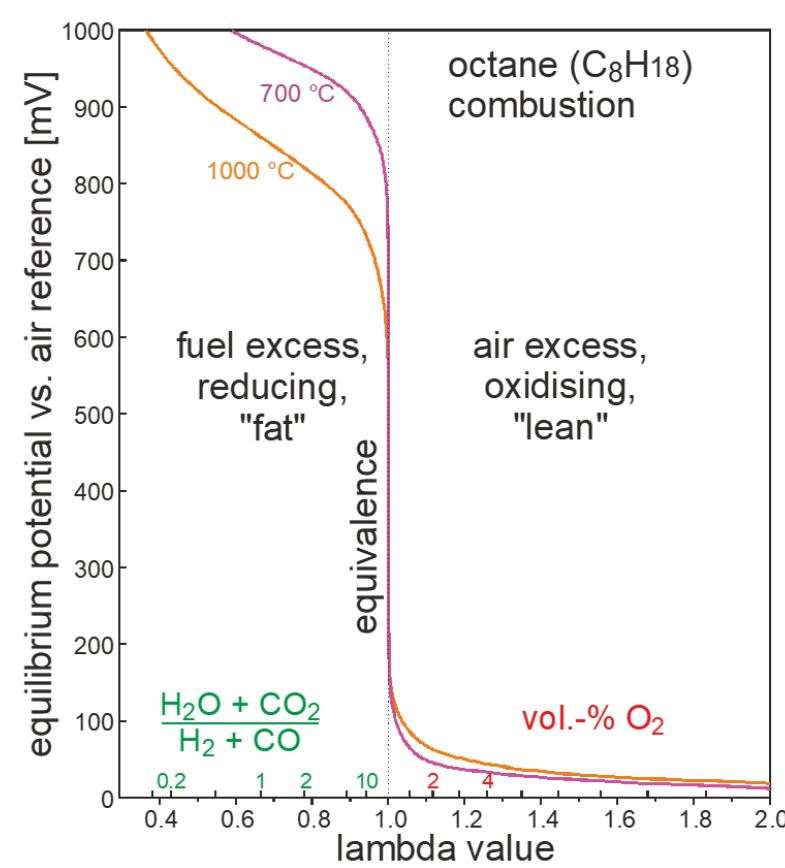

Figure 6. Measurement in reducing and oxidizing gases

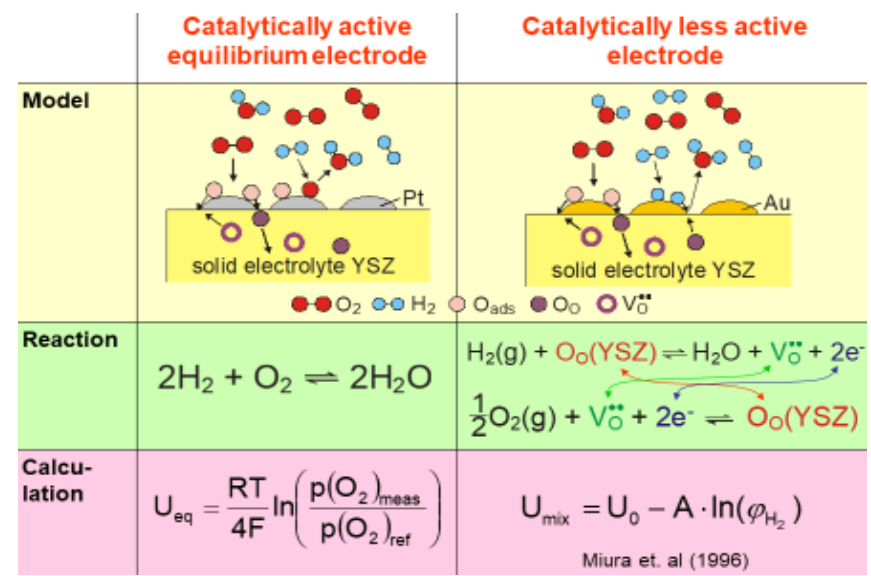

Figure 7. Comparison of mechanism between an equilibrium electrode (left) and a mixed potential electrode (right)

It was established that beside the morphology, the electronic and ionic defects in such substituted oxides play an important role for sensitivity and selectivity optimization and trimming [17-19]. The main drawback of all mixed potential sensors is their quite high cross-sensitivity to sulfur dioxide as well as long term stability in severe combustion flue gas environment [1]. Often carbon monoxide equivalent expression " $\mathrm{CO}_{\mathrm{e}}$ " is applied to these sensors meaning CO concentration response used for the calibration.

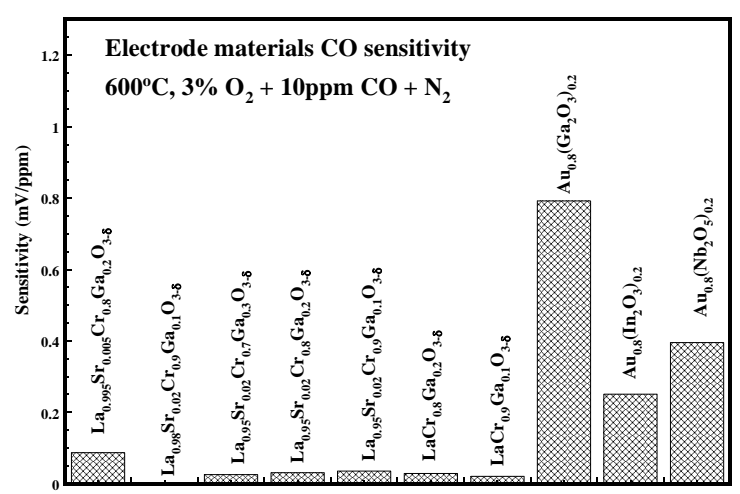

Figure 8. Composite materials sensitivity to CO [15]

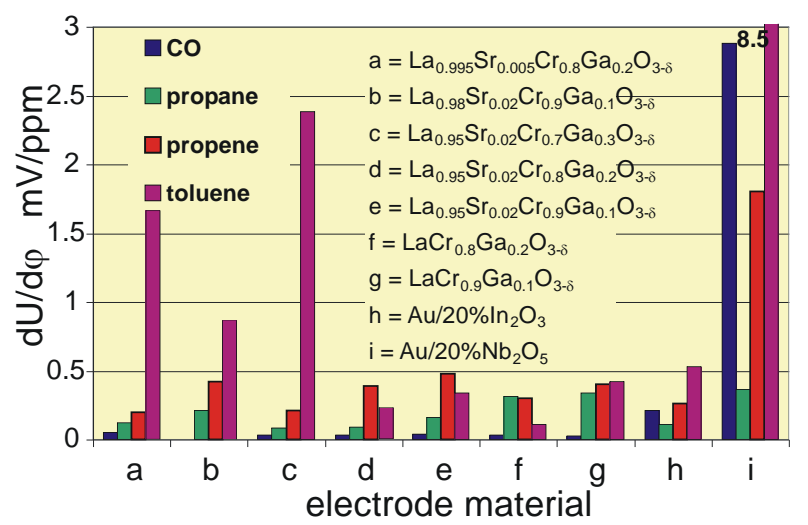

Figure 9. Sensitivity of different electrode materials to combustibles [17]

\section{Calorimetric catalytic sensors for combustibles $\left(\mathrm{CO}, \mathrm{CH}_{4}\right)$}

In sensors using calorimetric effects by catalytic turnover of combustibles such as $\mathrm{CO}$ or methane, two resistance temperature detectors (RTD) are compared. On of this is covered with catalytically active layer, e.g., platinum. The catalyst film is merged with RTD using highly thermally conductive packaging oxide materials to ensure more efficiently heat transfer of the combustion reaction on catalyst film to RTD. The surface of the other one is catalytically inactive. The reaction heat of the active resistor leads to an increase of temperature linearly proportional to the concentration of combustibles $[20,21]$. 
Oxidation reaction occurs between combustible species and oxygen with defined heat released is depending highly on the combustible concentration. Calorimetric catalytic CO-sensor can measure CO-concentration down to ppm level with detection limit $\sim 5 \ldots 10 \mathrm{ppm}$ CO. This technology is permitting fast and precise (Figure 10) $< \pm 25$ ppm CO or $5 \%$ of the reading measurements in flue gas up to $\sim 1750{ }^{\circ} \mathrm{C}$ temperature.

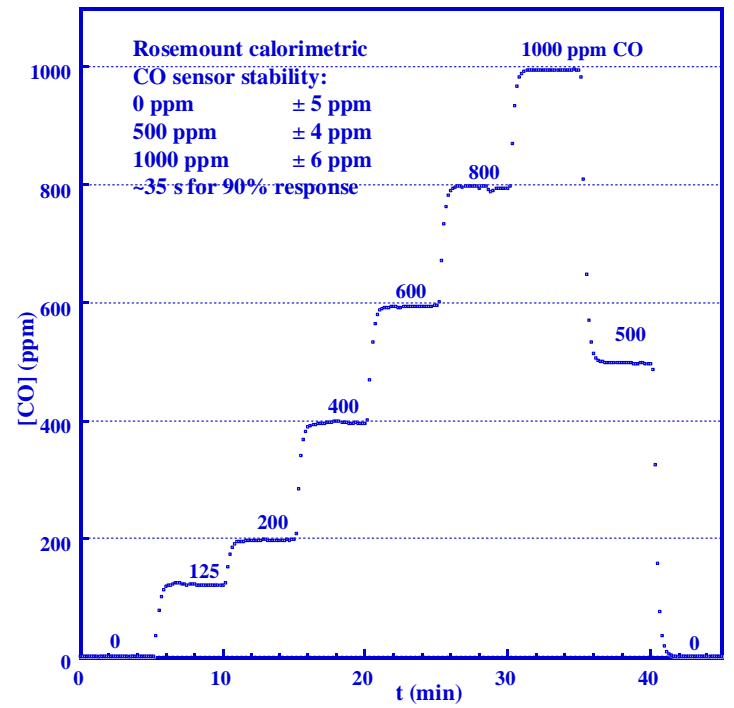

Figure 10. Calorimetric catalytic CO-sensor response at low CO concentration [1]

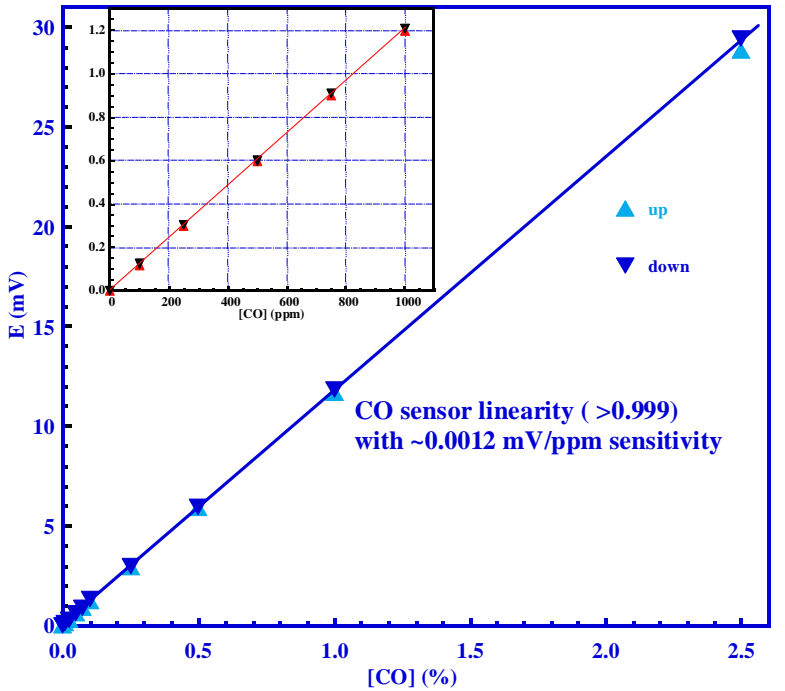

Figure 11. Calorimetric CO-sensor linearity [1]

Calorimetric CO-sensor has good $>99.9 \%$ linearity (Figure 11) and reproducibility (Figure 12) in a wide $\mathrm{CO}$ concentration range up to $2.5 \% \mathrm{CO}$ but to improve accuracy a calibration would be always recommended using upper limit of $\mathrm{CO}$ concentration measurement range. Calorimetric catalytic COsensor is highly flow-sensitive and gas flow stabilization and a flow sensor should be implemented to improve CO-sensor reliability in extractive combustion analyzer [1].

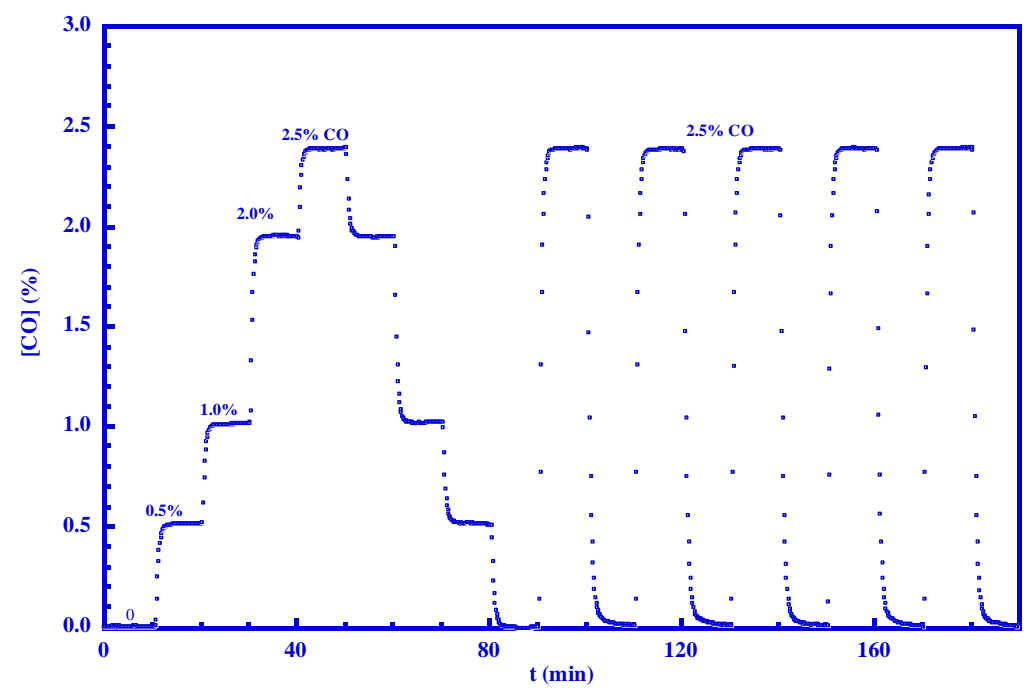

Figure 12. Calorimetric catalytic CO-sensor response at high $\mathrm{CO}$ concentration

Conventional catalysts for calorimetric methane sensors and combustion reaction are based on noble metals, i.e., palladium (Pd) or platinum ( $\mathrm{Pt})$ deposited on oxides such as cerium oxide $\left(\mathrm{CeO}_{2}\right)$ or metals. A calorimetric catalytic $\mathrm{CH}_{4}$ sensor has a good linearity (Figure 13) and $\sim 30$ s response for $90 \%$ signal (Figure 14). Flue gas flow control extractive environment would contribute to $\mathrm{CH}_{4}$ 
detection reliability with better accuracy and reproducibility in the very challenging temperature, pressure, flow and chemicals flue gas combustion environment [20].

Only two available major methane gas sensing technologies - catalytic calorimetric and TDLS/QCLS - have so far found practical application in instrumentation on market because they produce quite reliable and accurate (about $2 . . .5 \%$ error) values in the extractive or across the stack mode.

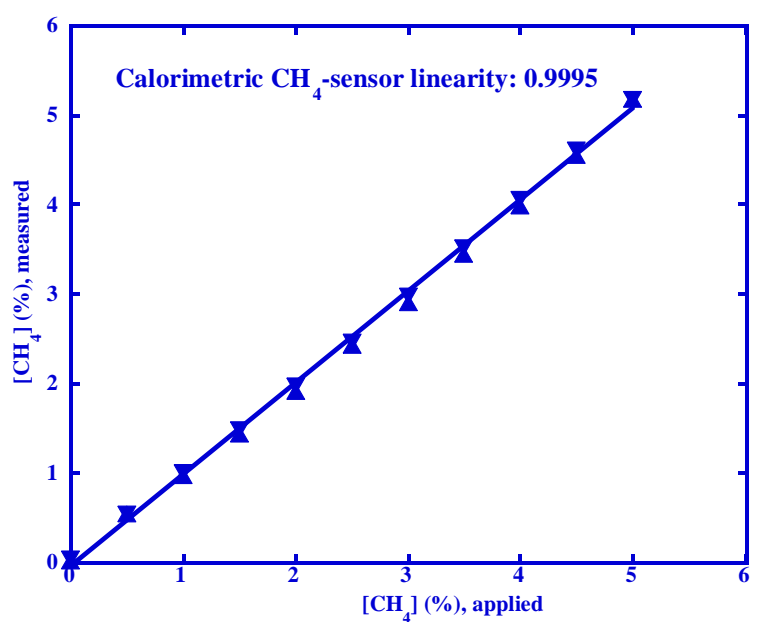

Figure 13. Calorimetric catalytic $\mathrm{CH}_{4}$-sensor linearity [20]

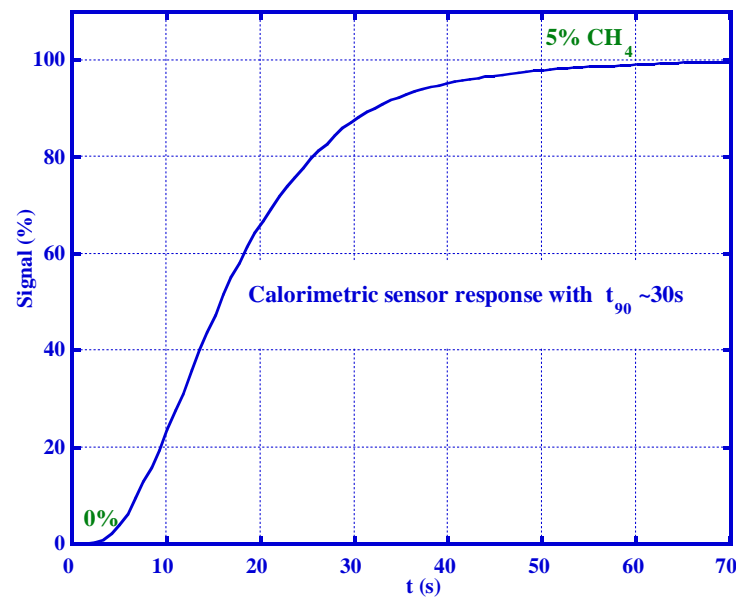

Figure 14. Calorimetric catalytic $\mathrm{CH}_{4}$-sensor response [20]

\section{Tunable diode laser spectroscopy (TDLS) for $\mathrm{CO}, \mathrm{CH}_{4}$ and oxygen measurements}

Tunable diode laser (TDL) and quantum cascade laser ( $Q C L$ ) spectroscopies are innovative optical measurement techniques utilizing lasers with different wavelength (Figure 15), e.g., tunable diode and quantum cascade [22-27].

TDL and QCL spectroscopies are highly distinguished from the conventional process photometry with the laser's ability to be scanned across the narrow combustion species absorption peaks many times per second by trimming the current through the laser. With a typical scan in the range of 0.2 to $0.3 \mathrm{~nm}$, the laser would provide much higher selectivity in applications. The IR absorption spectrum of oxygen $\left(\mathrm{O}_{2}\right)$, carbon monoxide $(\mathrm{CO})$ and methane $\left(\mathrm{CH}_{4}\right)$ is like a fingerprint, providing gas identification at different detection wavelengths (see Figure 16 for $\mathrm{O}_{2}$ ).

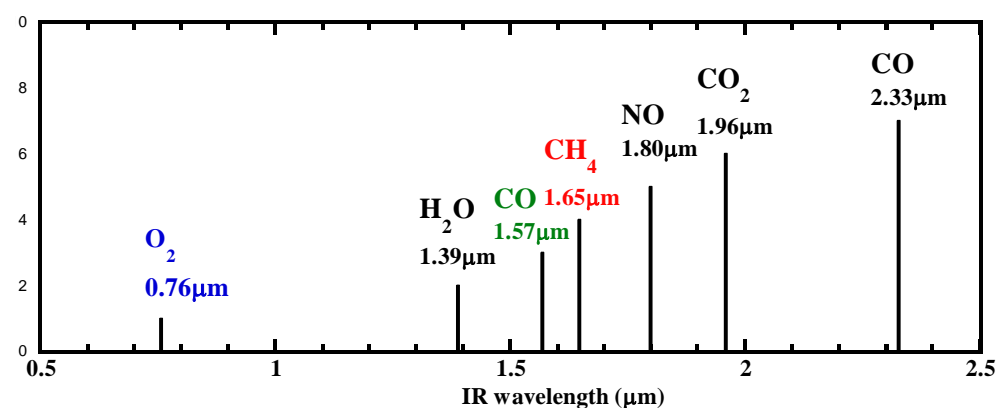

Figure 15. IR spectrum for different gases [27]

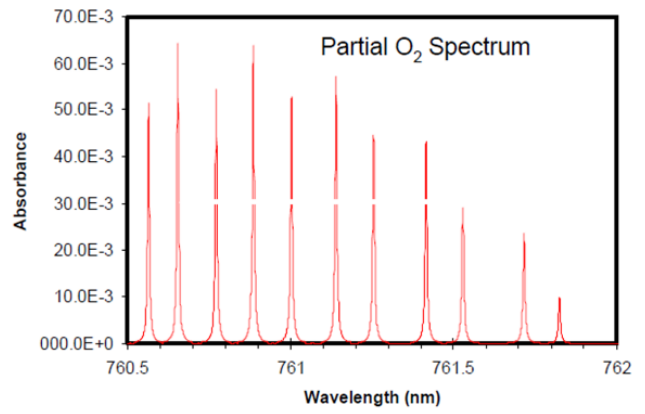

Figure 16. Oxygen absorption A-band [28]

The detection wavelengths and limits of some combustion gases are summarized in Table 1.

A series of process adaption application tools were developed for in-situ, extractive or in crosspipe installations. The probe design would not require a special optical path alignment but would deliver single point measurement. In the probe design the laser source and detector are located in the probe housing with the laser beam being reflected at the probe end, back to the detector by 
quartz prism, with max operation temperature of $<250{ }^{\circ} \mathrm{C}$ or by gold mirror with max operation temperature of $<430{ }^{\circ} \mathrm{C}[20]$.

Table 1. Combustion gases absorption lines and detection limits [20]

\begin{tabular}{ccc}
\hline Target gas & Wavelength $(\mu)$ & Detection limit $(\mathrm{ppm})$ \\
\hline Methane $\left(\mathrm{CH}_{4}\right)$ & $1.65(\mathrm{TDL})$ & 0.15 \\
& $7.9(\mathrm{QCL})$ & 0.003 \\
\hline & 1.57 & 30 \\
Carbon monoxide $(\mathrm{CO})$ & 2.33 & 0.5 \\
& 4.80 & 0.01 \\
\hline Oxygen & 0.76 & 8.956 \\
\hline Carbon dioxide $\left(\mathrm{CO}_{2}\right)$ & 1.96 & 3 \\
\hline Nitric oxide $\left(\mathrm{NO}^{2}\right)$ & 1.8 & 60 \\
\hline Nitrogen dioxide $\left(\mathrm{NO}_{2}\right)$ & 2.65 & 1 \\
\hline Water $\left(\mathrm{H}_{2} \mathrm{O}\right)$ & 0.68 & 0.3 \\
\hline
\end{tabular}

With a unique folded-path design, the probes can be installed in almost all pipes and stacks with no alignment needed. The TDL or QCL analyzer can serve as a probe using deflection mirror or quartz prism (Figure 17) for single point near real-time measurement or would provide extractive measurement across the duct or pipe (Figure 18). Temperature and pressure variation in the process has to be compensated and might cause an additional error in the measurements. IR light reflection at high temperatures, combined with wide background radiation from the fire box and process windows fouling, might bring additional challenges in many applications. There are quite accurate TDL analyzers with $\sim \pm 1-2 \%$ error and ppm or even sub-ppm detection limits in some applications.

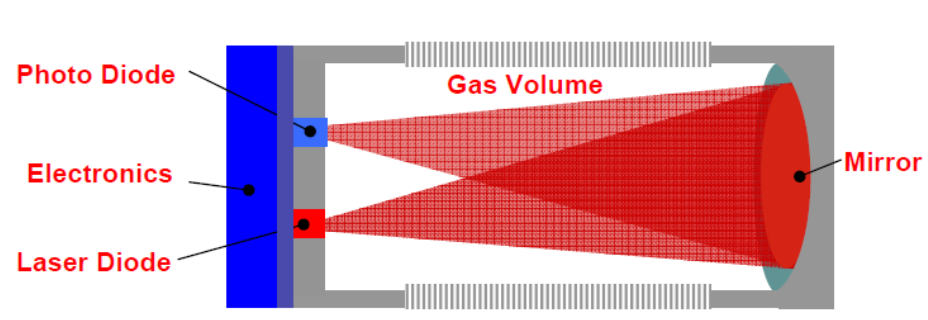

Figure 17. In-situ probe, $250-430^{\circ} \mathrm{C}$ limit (Au-mirror or quartz prism)

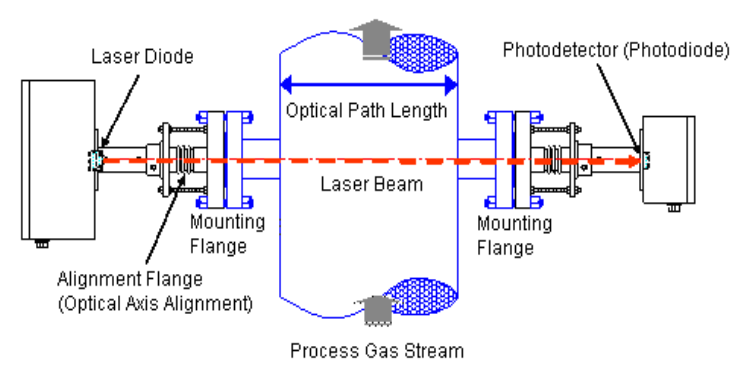

Figure 18. Across the stack installation [29]

However, laser analyzers are much more expensive with additional expensive and very timeconsuming installation compared to the zirconia $\mathrm{O}_{2}$-analyzers. TDL $\mathrm{O}_{2}, \mathrm{CO}$ and $\mathrm{CH}_{4}$ analyzers are mostly covering special chemicals production and very high $>1000^{\circ} \mathrm{C}$ temperature applications.

\section{Conclusions}

After more than 50 years, zirconia potentiometric oxygen gas sensing technology is still dominating combustion market with the high reliability, accuracy and low price. State of the art is the simultaneous measurement of oxygen and $\mathrm{CO}_{e}$ by means of one and the same probe. Calorimetric catalytic and mixes potential sensors are implemented for $\mathrm{CO}_{e}$ measurement. TDLS/QCLS are also applied for CO and for oxygen measurements. They are about 5 times more expensive compared to the zirconia $\mathrm{O}_{2}$-analyzers and additional require very expensive installation. TDLS $\mathrm{O}_{2}$ analyzers mainly cover the production of specialty chemicals and very high $>1000{ }^{\circ} \mathrm{C}$ 
temperature applications. TDLS/QCLS and calorimetric catalytic sensors are used in combustion process for methane measurement. Only two methane gas sensing technologies - catalytic calorimetric and TDLS/QCLS - have so far found practical application in instrumentation in the combustion market as in extractive devise or across the stack for in situ measurements.

\section{References}

[1] P. Shuk, C. McGuire, Sensors \& Transducers 217 (2017) 1-13

[2] N. Docquier, S. Candel, Progress in Energy and Combustion Science 28 (2002) 107-150

[3] Emerson comubstions analyzers, https://www.emerson.com/en-us/automation/measurementinstrumentation/gas-analysis/about-combustion-analysis, date accessed January 28, 2020.

[4] H. Peters, H.-H. Möbius, Procedure for the gas analysis at elevated temperatures using galvanic solid electrolyte elements, DD-Patent 21673 (1958)

[5] J. Weissbart, R. Ruka, Review of Scientific Instruments 32 (1961) 593-595

[6] H.-H. Möbius, in: Sensors a comprehensive survey, Vol. 3, W. Göpel, J. Hesse, J. N. Zemel, Eds., New York, VCH, 1992, p. 1105

[7] U. Guth, in: Electrochemical dictionary, A. Bard, G. Inzelt, F. Scholz, Eds., $2^{\text {nd }}$ extended Edition, Springer, Heidelberg, Dordrecht, London, New York, 2012, p. 400

[8] W. C. Maskell, Solid State lonics 134 (2000) 43-50

[9] S. Zhuiykov, Electrochemistry of zirconia gas sensors, CRC Press, Boca Raton, 2008, p. 320

[10] P. Shuk, Technisches Messen 77 (2010) 19-23

[11] P. Shuk, Ed Bailey, U. Guth, Sensors \& Transducers 90 (2008) 174-184

[12] P. Shuk, R. Jantz, H.-U. Guth, International Journal on Smart Sensing and Intelligent Systems 5 (2012) 233-245

[13] P. Shuk, R. Manoharan, T. Blanar, R. Molnar, M. Keyes, Sulfur resistant sensors, US-Patent 7,527,717 B 2 (2003)

[14] E. Flegel, C. Vonau, U. Guth, Technisches Messen 84 (2017) 635-643

[15] P. Shuk, E. Bailey, J. Zosel, U. Guth, Ionics 15 (2009) 131-138

[16] O. Driesner, F. Gumprecht, U. Guth, Journal of Sensors and Sensor Systems 6 (2017) 327-330

[17] U. Guth, H.-D. Wiemhöfer, in: Gas Sensors Based on Conducting Metal Oxides, N. Barsan, K. Schierbaum, Eds., Elsevier, Amsterdam, 2019, p. 13

[18] X. Zhang, H. Kohler, M. Schwotzer, U. Guth, Sensors \& Actuators B: Chemical 217 (2015) 107-112

[19] A. Ruchelts, N. Donker, D. Schönauer-Kamin, R. Moss, J. Zosel, U. Guth, M. Mertig, Sensors \& Actuators B: Chemical 290 (2019) 53-58

[20] P. Shuk, C. McGuire, E. Brosha, Sensors \& Transducers 229 (2019) 1-10

[21] P. Shuk, P. Murphy, in: Processing of the $1^{\text {st }}$ International Conference on Sensing Technology, Palmerston North, New Zealand, 21-23 November 2005, p. 226

[22] E. D. Hinkley, P.L. Kelley, Science 171 (1971) 635-639

[23] K.W. Nill, F.A. Blum, A.R. Calawa, T.C. Harman, Applied Physics Letters 19 (1971) 79-82

[24] R. M. Mihalcea, D. S. Baer, R. K. Hanson, Applied Optics 36 (1997) 8745-8752

[25] G. B. Rieker, J. B. Jeffries, R. K Hanson, Applied Optics 48 (2009) 5546-5560

[26] R. K. Hanson, Proceedings of the Combustion Institute 33 (2011) 1-40

[27] P. Shuk, in: Sensors for Everyday Life, S. C. Mukhopadhyay et al. Eds., Springer, Heidelberg - New York, 2017, p. 81

[28] Y. Krishna, S. O’Byrne, J. Kurtz, Applied Optics 53 (2014) 4128-4135

[29] Yokogawa Electric Corp. http://www.yokogawa.com/an/faq/tdls/spec 1.htm

(C)2020 by the authors; licensee IAPC, Zagreb, Croatia. This article is an open-access article distributed under the terms and conditions of the Creative Commons Attribution license (http://creativecommons. org/licenses/by/4.0/) 